\title{
PLANETA ROODA: uma nova prototipagem baseada na WEB 2.0
}

\author{
Patricia Alejandra Behar \\ Augusto Bergamaschi Rückert \\ Daniel Corrêa \\ Cristina Alba Wildt Torrezza
pbehar@terra.com.br, augustodesign@gmail.com, danielcorrea.rs@gmail.com, crisaaw@yahoo.com.br

Resumo: A socialização da internet gera uma facilidade de acesso às informações e maior interação entre as pessoas, antes limitada por distanciamentos culturais ou geográficos. A educação, por sua vez, acompanha essas modificações da sociedade, tentando se inovar a passos muito lentos. Dentro deste quadro de mudanças, o Planeta ROODA 2.0 surge como uma forma de unir a tecnologia da web com a interação social e autônoma do usuário, possibilitando que o aluno construa o seu conhecimento e valorize o seu aprendizado. Desse modo, este estudo propõe a elaboração de um ambiente virtual de aprendizagem baseado na Web 2.0.

\section{Palavras-chave do Autor}

Ambiente virtual de aprendizagem, Web 2.0, educação a distância, relação homemmáquina, aprendizagem.

\section{PLANET ROODA: a new prototype based on WEB 2.0}

Abstract: The socialization of internet has been making it easier for people to access information and interact with each other, which is something that was very difficult before due to cultural or geographic limits. Because of all those changes, Education has been trying to remain up-to-date, through a slow process. PLANET ROODA 2.0 aims to put web technology, social interaction and user autonomy together in order to make students able to build up and valorize their learning processes. Moreover, this study proposes the elaboration of an e-learning environment based on web 2.0.

\section{Keywords}

E-learning environment, Web 2.0, distance education, human-computer interaction, learning process.

\section{Introdução}

A Internet deixou de ser somente uma ferramenta de trabalho, destinando-se também a diversão e socialização. Ferramentas como Orkut e Facebook permitem a atuação dos usuários no mundo virtual interagindo com contatos e grupos de preferência, oferecendo ainda uma página web para todos os que desejam tornar-se visíveis neste espaço digital. Já softwares como Second Life possibilitam, além das funções citadas, a criação de um personagem, denominado avatar, que fornece recursos para maior interação entre usuários, interatividade com ambientes fictícios, capacidade de personalização e ações mais próximas da realidade.

Uma nova prototipagem para o Planeta ROODA mostrou-se necessária para congregar 
os paradigmas identificados na atual configuração das redes virtuais, a denominada Web 2.0 ${ }^{1}$. Busca-se, com isso, transgredir os limites de um ambiente virtual de aprendizagem (AVA) para níveis além de fronteiras existentes, atingindo as áreas dos softwares sociais e dos MMORPGs ${ }^{2}$.

\section{Conhecendo o Planeta ROODA}

O Planeta ROODA é um Ambiente Virtual de Aprendizagem disponível via web, voltado à Educação Infantil e ao Ensino Fundamental. Caracteriza-se pela temática espacial, possibilitando configuração da interface gráfica pelo usuário e a opção de selecionar as ferramentas que mais se adaptam a sua metodologia de trabalho: comunicação síncrona - através das ferramentas de Bate-Papo e Comunicador - e comunicação assíncrona - como o Fórum, o trabalho coletivo através da ferramenta Projetos e a publicação de arquivos na Biblioteca. Encontra-se disponível em http://homer.nuted.edu.ufrgs.br/planeta.

Atualmente, este ambiente virtual funciona através de uma interface gráfica estática, implementada em linguagens php e html. Os acessos são efetuados somente através de linkagens internas, sem abertura a espaços virtuais externos. As turmas são criadas e gerenciadas por usuários com nível de administrador, que habilitam outros usuários com níveis de professor ou aluno, abrindo ou não, a possibilidade de configuração das ferramentas por estes usuários.

\section{Em busca de uma nova prototipagem para o Planeta ROODA 2.0}

O Planeta ROODA 2.0 baseia-se nas novas tendências da rede mundial. Sendo assim, a intenção não trata apenas da criação de um novo conceito em plataforma educacional, mas da ampliação do seu espaço para um maior contato entre professor e aluno, não limitando a interação por turmas e dando suporte ainda para visitas intranet entre escolas. Isso é possível porque todo sistema é baseado em um ambiente para comunicação entre usuários em tempo real, utilizando-se de uma ferramenta desenvolvida para tal fim que mescla vários utilitários, como bate-papo, programa de comunicação instantâneo e apresentação social de usuários. Para as visitas entre turmas e/ou entre escolas o Planeta 2.0 conta com uma sistemática diferenciada de autorizações de acesso, que permite conceder ambientes inteiros aos utilizadores, onde cada um pode personalizar e gerenciar novas autorizações de acesso aos objetos ou ainda ceder um novo ambiente a outros usuários dentro do seu ambiente. $\mathrm{O}$ sistema ainda possui, além da manipulação das ferramentas educacionais já contidas nele, a linkagem externa de outros objetos educacionais, bem como utilitários da web. Todos esses fatores garantem ao Planeta ROODA 2.0 a possibilidade de crescimento sem limite, alimentado pela inteligência coletiva ${ }^{3}$.

\footnotetext{
${ }^{1}$ Web 2.0 é um termo usado para designar uma segunda geração de comunidades e serviços baseados na plataforma Web. Embora o termo tenha uma conotação de uma nova versão para a Web, ele não se refere à atualização nas suas especificações técnicas, mas a uma mudança na forma como ela é entendida por usuários e desenvolvedores. A regra mais importante é desenvolver aplicativos que aproveitem os efeitos de rede para se tornarem melhores quanto mais são usados pelas pessoas, aproveitando a inteligência coletiva.

${ }^{2}$ MMORPG é um jogo de interpretação de personagem online e em massa para múltiplos jogadores. Permite a milhares de jogadores a criação síncrona de personagens em um mundo virtual dinâmico na Internet.

${ }^{3}$ Termo definido por Pierre Lévy (apud Toben e Wolf, 1997).
} 
Através da adoção de avatares, comumente encontrados em softwares sociais, como Second Life e, mais especificamente, o Lively e MMORPGs, como World of Warcraft e o Ragnarok, o Planeta ROODA 2.0 propõe uma navegação ampliada, com maior gama de opções de acesso. O sistema criado caracteriza-se pela existência de dois modos de navegabilidade, uma utilizada pelo usuário diretamente nas interfaces de funcionalidades, e outra efetuada através do avatar no ambiente metafórico. O usuário acessa as telas de funcionalidades pela entrada do avatar nas construções virtuais (casas e prédios) existentes no ambiente. $\mathrm{O}$ uso das ferramentas ocorre através de interfaces gráficas integradas ao sistema. Dividir as atividades por tela e por avatar permite trabalhar com mais informações ao mesmo tempo, podendo gerenciar situações síncronas e assíncronas nos âmbitos sociais e funcionais da plataforma. A habilitação de atalhos abre a possibilidade dos usuários que não queiram navegar com o avatar ou busquem acessos mais facilitados, utilizarem somente as interfaces de funcionalidades através do menu de navegação fornecido pelo sistema.

Como metodologia projetiva foi selecionado o DIP (Desenvolvimento Integrado de Produto) (Ulrich e Eppiger, 2000) para, então, contemplar todos os aspectos necessários ao desenvolvimento multidisciplinar, evitando defasagens de abrangência nas áreas de trabalho envolvidas. A análise de material já existente, como a versão anterior do software, feedbacks obtidos dos cursos realizados através deste, bibliografia especializada, entre outros, serviram de base para a pesquisa na fase de pré-projeto. A nova prototipagem está sendo desenvolvida por uma equipe interdisciplinar do NUTED $^{4}$, composta por programadores, designers e profissionais da educação.

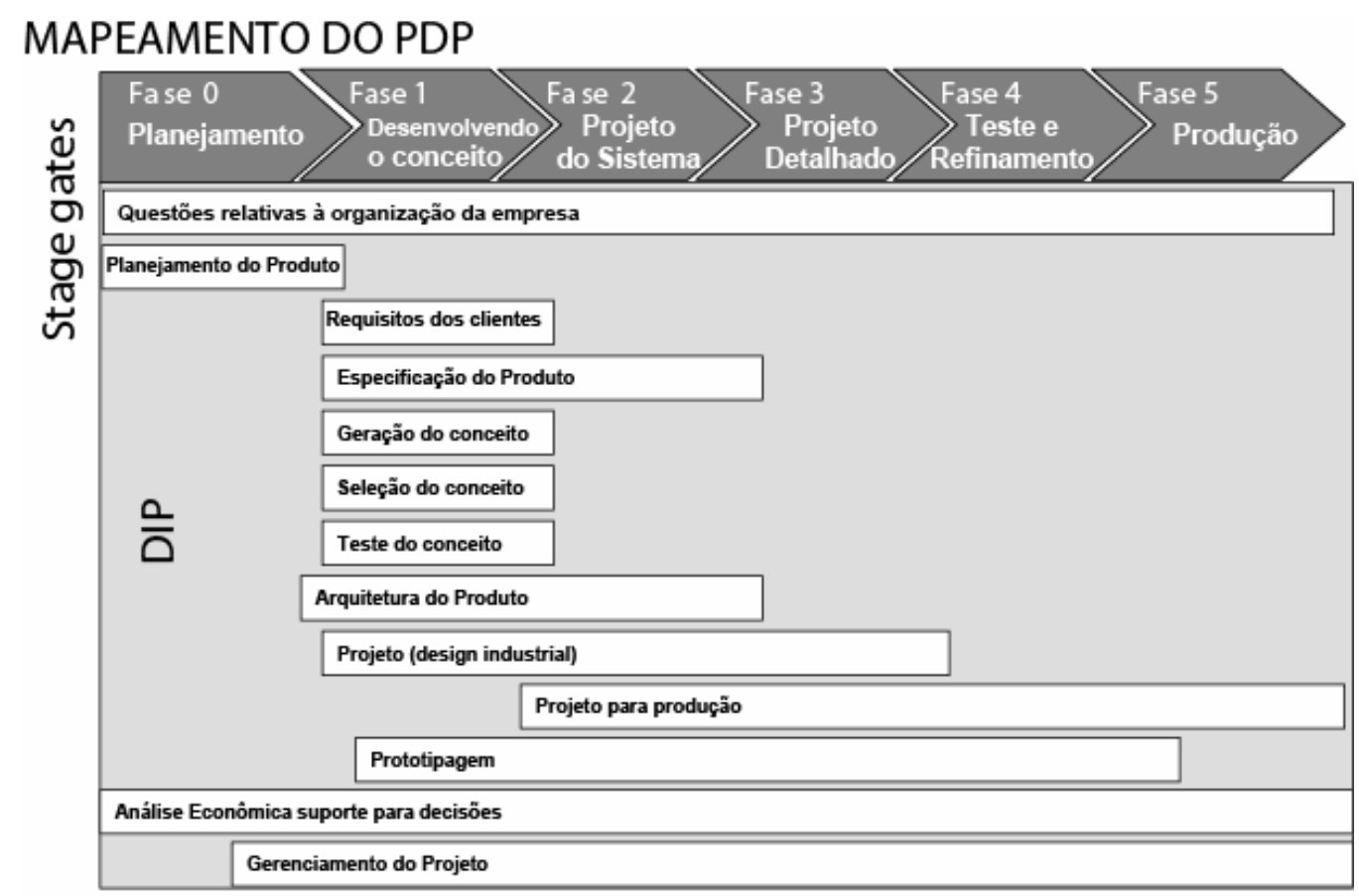

Modelo Proposto por Ulrich \& Eppiger (2000)

Figura 1 - Mapeamento da metodologia.

\footnotetext{
${ }^{4}$ Núcleo de Tecnologia Digital aplicada à Educação, da Faculdade de Educação. Disponível em http://www.nuted.edu.ufrgs.br.
} 
O DIP (Figura 1) apresenta as atividades em Engenharia Simultânea ${ }^{5}$, transcorrendo os processos concomitantemente. Esse enfoque permite que o desenvolvimento do Planeta ROODA ocorra mais rápido, exigindo um maior envolvimento da equipe a fim de evitar inconsistências.

\subsection{Construindo a Estrutura}

O sistema administrativo objetiva ser flexível, visto que deve suportar situações incomuns aos sistemas em geral. O planejamento do Planeta ROODA 2.0 baseia-se na teoria dos multiversos (Melo, 2003), que consiste na existência de universos virtuais dentro de outros universos virtuais com autorizações herdáveis. O acesso ao Planeta ROODA 2.0 ocorre inicialmente através de um administrador, que é nomeado durante a instalação do sistema. Ele é o responsável pelo controle e personalização dos ambientes dessa plataforma, através do Módulo de Construção do ambiente. O Módulo permite a inserção de objetos pré-definidos contendo as ferramentas do Planeta, fornecendo conteúdo ao seu ambiente. Após essa primeira etapa, ele poderá criar um ou mais universos vinculados ao seu de origem. Nesses outros universos há outros administradores, cadastrados e inseridos pelo primeiro. Cada um desses administradores do multiverso também poderá personalizar seu ambiente, assim como conceder outros universos a outros usuários cadastrados. Porém, ele nunca poderá alterar o ambiente de onde derivou a não ser que essa autorização lhe seja fornecida e o dono do ambiente, que por sua vez poderá alterar seu ambiente conforme necessário. Esse vínculo é passado aos universos posteriormente criados, ou seja, o administrador do primeiro universo será também o administrador do segundo universo gerado através do primeiro e também do terceiro gerado através do segundo e assim sucessivamente. Os outros níveis administrativos que são: coordenador, supervisor, professor e aluno, também são herdáveis. Assim, cada nível inferior não tem permissão de alterar as ações dos superiores, sendo limitado por estes. Os usuários que não forem classificados por esses níveis serão considerados visitantes, podendo somente trafegar entre os universos e ter acesso aos objetos distribuídos nesses ambientes (se o administrador assim o desejar), não podendo editar nada.

As limitações espaciais e de compatibilidade hierárquica foram dissolvidas, deixando o sistema crescer sem limites fixos, porém com regras administrativas e funcionais asseguradas, sendo a expansão apenas restringida pela memória do banco de dados. Através dessa nova proposta de prototipação objetiva-se possibilitar a interação mais dinâmica entre os usuários, fazendo com que alternem a sua condição (nível) aluno/professor em determinadas turmas e que os objetos no ambiente possam ser acessados ou visualizados por uma determinada classe de usuários e por outra não. Esse cenário provém da necessidade de haver uma hierarquia onde, ao mesmo tempo todos possam contribuir para o crescimento dos ambientes, sendo a organização feita por qualquer nível de usuário, e esses modos de personalização concedidos pelo administrador de cada universo.

\footnotetext{
${ }^{5}$ Engenharia Simultânea é uma abordagem sistemática para o desenvolvimento integrado de produtos que enfatiza o atendimento das expectativas dos clientes. Inclui valores de trabalho em equipe, tais como cooperação, confiança e compartilhamento, de forma que as decisões sejam tomadas, no início do processo, em grandes intervalos de trabalho paralelo incluindo todas as perspectivas do ciclo de vida, sincronizadas com pequenas modificações para produzir consenso (Prasad, 1996).
} 


\subsection{Interface Gráfica e Identidade Visual}

Devido à caracterização da plataforma, foi escolhido manter a metáfora já utilizada na versão anterior do Planeta ROODA (Figura 2). Essa se baseia no conceito de Space Opera (Novela Espacial), como os cenários cinematográficos de Star Wars e Star Trek, ou dos desenhos animados Cowboy Bebop e Star Blazers. Porém para se adaptar à nova estrutura do software, foram analisadas as hierarquias funcionais dentro da identificação metafórica, e como o sistema de turmas, administração e níveis de usuários deveria participar nesse contexto. Geraram-se cinco propostas de organização compatíveis de onde foi selecionada a que mais se enquadrava pelos membros da equipe, guiados pelos elementos mais coerentes e atrativos para o público-alvo principal, alunos de educação infantil e séries iniciais (Lévy, 1999).

A prototipagem das telas foi o processo posterior à pesquisa e categorização dos itens exigidos na metodologia. Esta atividade possibilita simular situações de uso previamente, economizando tempo e eliminando algumas ações que não trariam resultados (Preece et al, 2005). Para as prototipagens de baixa fidelidade, efetuadas à mão livre, selecionaram-se as telas que conteriam mais informações, com a preocupação de analisar o espaço existente para alocar esses dados e de como apresentá-los ao usuário, permitindo acesso facilitado e uso rápido, sem sobrecarregá-lo cognitivamente. Para entender os caminhos que o usuário poderia fazer para acessar o ambiente, foi montada uma prototipagem de média fidelidade direcionada à ação, executada em um

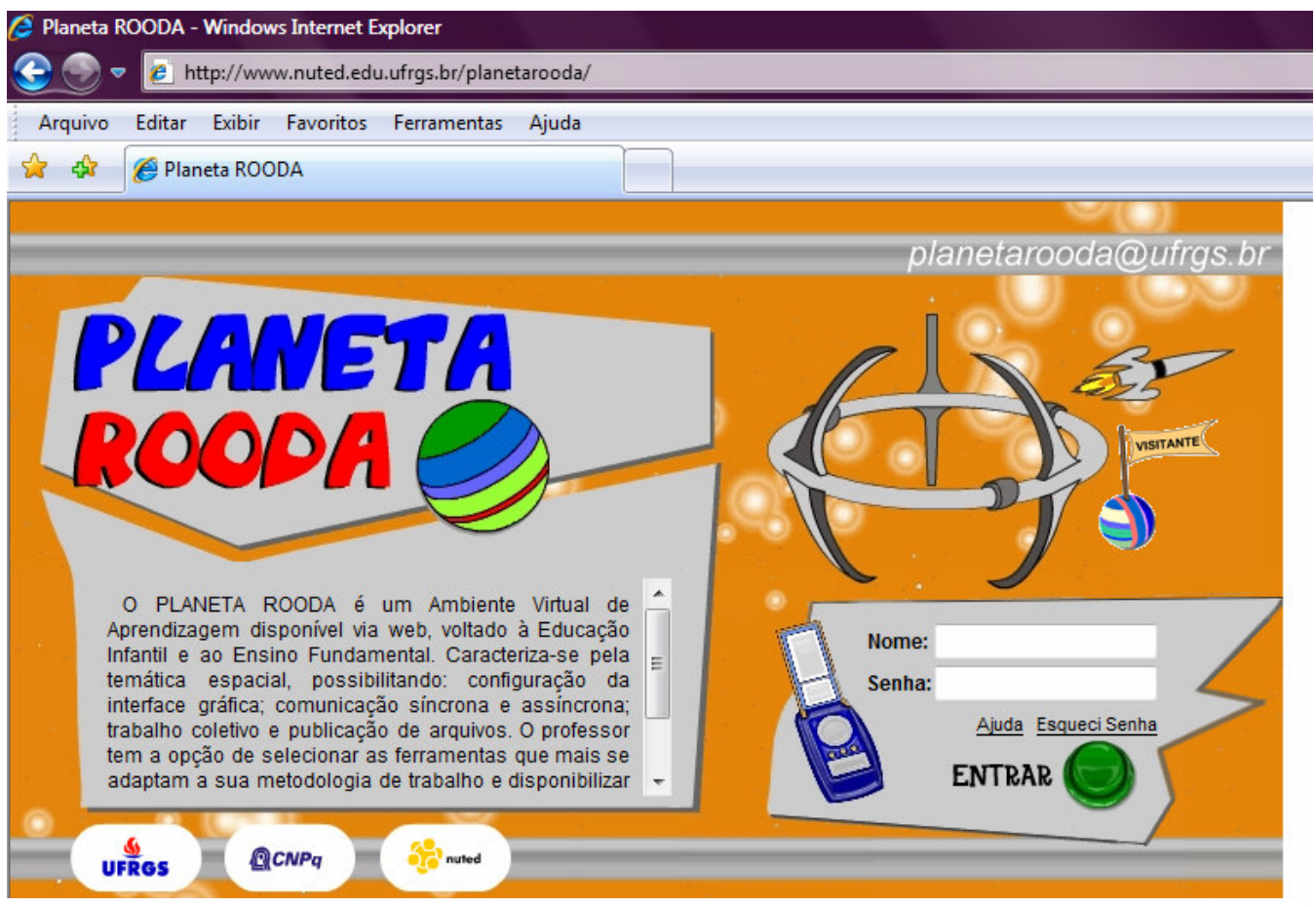

Figura 2 - Tela inicial do Planeta ROODA 1.

software de apresentação de slides, devido à rapidez em gerar telas e acessos variados. A categorização dos tipos de informações a serem expostas e sua posterior análise serviu para definir elementos que devem ser mantidos, quais se mostraram desnecessários e quais faltantes. 
Como fase conjunta, definiu-se construir uma nova identidade visual ${ }^{6}$ para o Planeta ROODA, com o objetivo de situá-lo dentro dos novos paradigmas educacionais, sociais e culturais. A intenção é possibilitar que a estrutura visual seja capaz de adaptarse às múltiplas aplicações em que será requerida, mesmo tratando-se de um sistema de grande amplitude como este (Figuras 3 e 4).

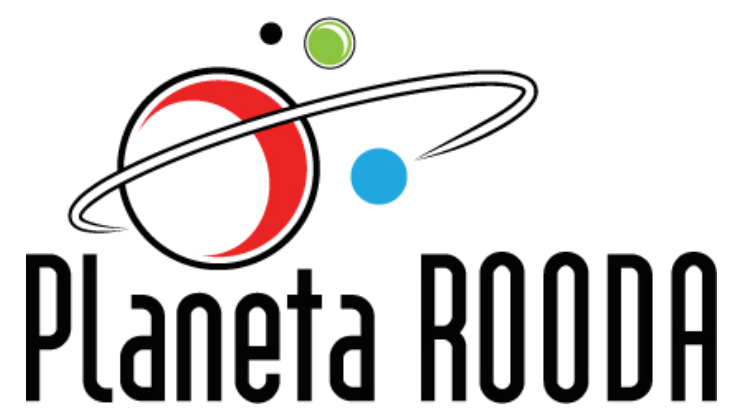

Figura 3 - Nova marca

(logotipo+símbolo) do Planeta ROODA.

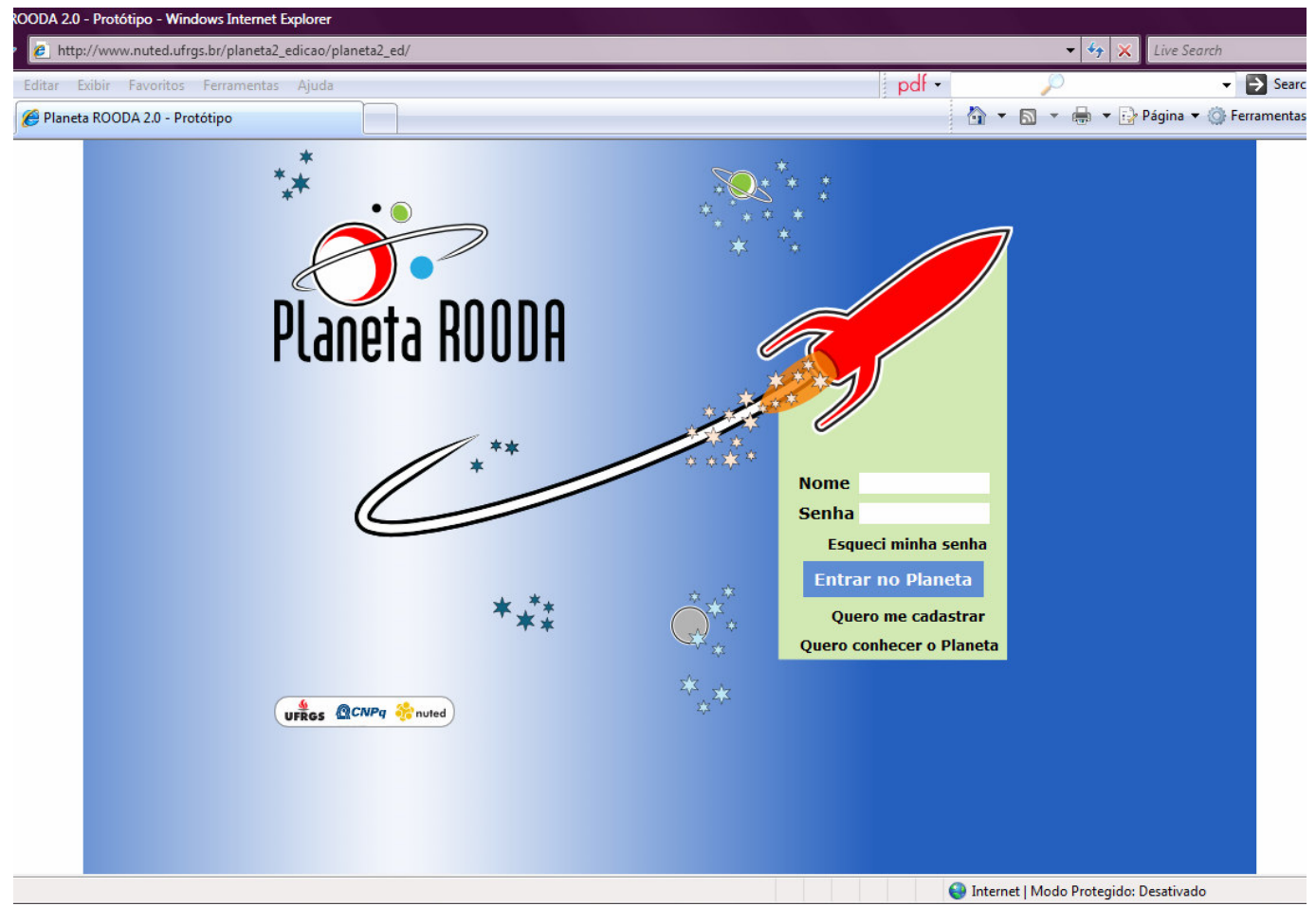

Figura 4 - Nova tela inicial do Planeta ROODA.

O projeto de identidade visual baseia-se na metáfora e na construção de elementos de rápida compreensão, com objetivo de ser fonte de referência para a hierarquização dos elementos gráficos das interfaces. Através de formas básicas, os símbolos que constituem a nova identidade visual do planeta simbolizam um planeta e seu satélite natural, com a órbita grifada como um anel planetário, possibilitando a

\footnotetext{
${ }^{6}$ Entende-se por Identidade Visual o conjunto de elementos gráficos, definidos com o fim de simbolizar e transmitir as informações do sistema que representa. É composta pela logotipia, grafismos e tipografia.
} 
associação a corpos celestes característicos por possuírem anéis, como Saturno. Os grafismos no horizonte dos elementos principais equilibram o peso do símbolo e remetem à possibilidade de mais satélites como também de mais planetas ao fundo, permitindo a informação dúbia, tendo como argumentação o sistema de multiverso do novo Planeta ROODA.

\subsection{O Protótipo}

Dentro da metodologia selecionada, os procedimentos iniciais de pesquisa e análise foram realizados conjuntamente com o início da construção do ambiente de navegação com avatares (Figura 5). Este formatado através de testes das possibilidades e limitações das linguagens de programação escolhidas, PHP e ActionScript, e a construção de um banco de dados MySQL para gerenciar as informações. No novo Planeta ROODA todas as interfaces e interações são programadas e executadas em Flash ${ }^{7}$, através de objetos gráficos e programação ActionScript. Os dados são requisitados à programação PHP, que busca as informações no banco de dados MySQL, devolve ao PHP e este informa as alterações ao ActionScript.

Conforme comentado anteriormente, como processo paralelo, a análise de dados foi executada através da hierarquização de requisitos dos usuários obtidos em pesquisa. A hierarquia foi formulada a partir da dependência das informações obtidas, gerando relacionamentos diretos e indiretos. Para visualização de onde os fatores devem ser trabalhados, os requisitos foram separados em três classes: acessibilidade, usabilidade e interatividade.

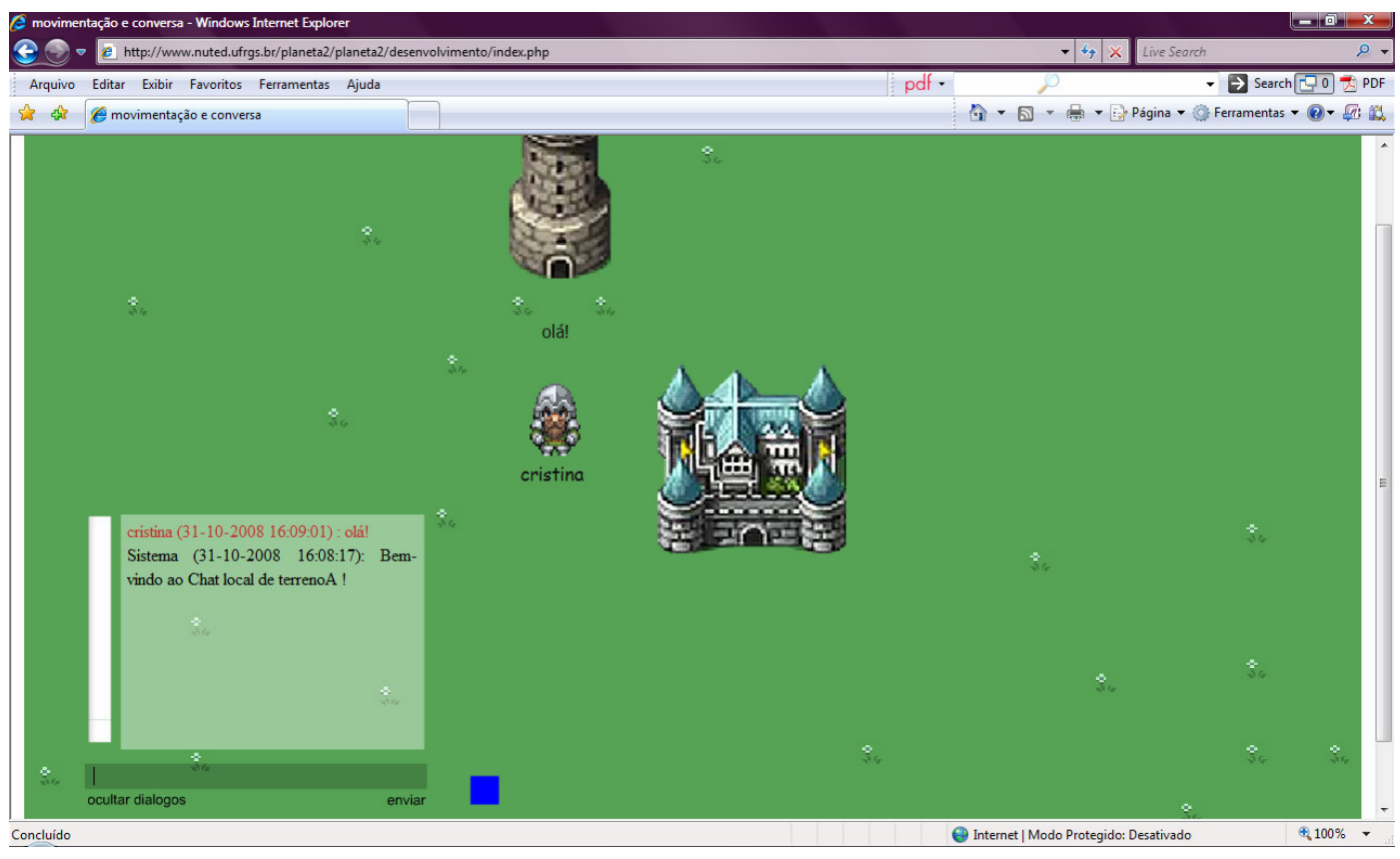

Figura 5 - Tela do protótipo do ambiente de navegação.

\footnotetext{
${ }^{7}$ Software de gráficos vetoriais da Adobe para criação de animações interativas embutidas em navegador web.
} 
Atualmente, a geração das telas estáticas está em fase de construção do wireframes $^{8}$, que servem de base para análise funcional, antes da aplicação das informações visuais. O protótipo do Planeta ROODA 2.0 (figura 5) encontra-se em desenvolvimento e disponível para teste em http://www.nuted.ufrgs.br/planeta2.

\section{Considerações Finais}

Através das tecnologias digitais, limites sociais e territoriais estão mais dissolvidos. A partir disso, o Planeta ROODA 2.0, apropria-se de recursos digitais similares aos aplicados em plataformas da atualidade como o Orkut, Second Life, entre outros, objetivando ultrapassar o paradigma do simples repositório de materiais didáticos, construindo uma ferramenta baseada na interação, socialização e na construção compartilhada do saber. Através da configuração de elementos dos ambientes pelos usuários, o Planeta ROODA possibilita a personalização, colaborando na identidade do usuário com cada um dos ambientes. A utilização de avatares permite a projeção do aluno no referido ambiente, colaborando, inclusive, na conquista de uma maior afetividade na relação homem-máquina. A partir da comunicação entre professores e alunos de diferentes turmas possibilita-se um ensino interdisciplinar, fornecendo maior liberdade às dinâmicas pedagógicas aplicadas ao AVA. Na manipulação de cenários em tempo real, aproxima os usuários da metáfora aplicada, assim como também facilita o entendimento e a utilização das funcionalidades do Planeta ROODA e dinamiza a interação entre usuários. Portanto, o Planeta ROODA objetiva, a partir da web 2.0, colaborar com a sociedade acadêmica, utilizando a tecnologia digital para construir uma nova concepção de ambiente virtual de aprendizagem, visando a criação e implementação de um saber compartilhado em tempo real.

\section{Referências Bibliográficas}

LÉVY, Pierre. A inteligência coletiva: por uma antropologia do ciberespaço. Tradução: Luiz Paulo Rouanet. 2.ed. São Paulo: Loyola, 1999.

MELO, Amanda Meincke. Uma abordagem semiótica para o design de portais infantis com a participação da criança. Campinas,S.P, 2003.

PRASAD, B. Concurrent engineering fundamentals: integrated product and process development. v. 1. New Jersey, Prentice Hall. ( t: 321 ). 1996.

PREECE, J. ; ROGERS, Y.; SHARP, H. Design de Interação: Além da Interação Homem-Computador. Porto Alegre, RS, Artmed: 2005.

TOBEN, Bob ; WOLF, Fred Alan. Espaço-Tempo e Além: Bob Toben e Fred Alan Wolf em conversa com físicos teóricos. Editora Cultrix: 1997.

ULRICH, K. T. e EPPIGER, S. D. Product Design and Devolopment. United States of America: Irwin McGraw - Hill Companies, 2nd ed., 2000.

\footnotetext{
${ }^{8}$ Denominação de documento estrutural para o conteúdo de páginas. Serve para indicar pesos e
} relevâncias entre conteúdos. 